\title{
Dietary Fats and Oils: Some Evolutionary and Historical Perspectives Concerning Edible Lipids for Human Consumption
}

\author{
Dante Roccisano $^{1 *}$, Jaliya Kumaratilake1, Arthur Saniotis ${ }^{1,2,3}$, Maciej Henneberg ${ }^{1,2,3}$ \\ ${ }^{1}$ Discipline of Anatomy and Pathology, School of Medicine, University of Adelaide, Adelaide, Australia \\ ${ }^{2}$ Biological and Comparative Anatomy Unit, School of Medicine, University of Adelaide, Adelaide, Australia \\ ${ }^{3}$ Institute of Evolutionary Medicine, University of Zurich, Zurich, Switzerland \\ Email: *dante.auni@gmail.com
}

Received 3 May 2016; accepted 19 July 2016; published 22 July 2016

Copyright (C) 2016 by authors and Scientific Research Publishing Inc.

This work is licensed under the Creative Commons Attribution International License (CC BY). http://creativecommons.org/licenses/by/4.0/

(c) (i) Open Access

\begin{abstract}
Consumption of fats and oils in the ancient world was examined as a window to human nutritional needs and compared with lipid usage in the modern world, post-1900. In earlier periods, the natural and only source of edible fats and oils came from both animals and plants. These fats and oils played a vital role in the evolution of the human body structure, supporting many biochemical functions. Artifacts from prehistoric periods and the ancient world had indicated that humans were evolutionarily adapted to consume saturated lipids. They also consumed unsaturated fats and oils extracted from animals and plants, now identified as omega- 3 to omega- 6 in the fatty acid ratio of 1:1, commonly derived from naturally consumed unprocessed products and food sources. These fats and oils assisted in providing the ingredients for the building up of cells and maintaining their structural integrity in tissues, including the brain and other important internal organs, as well as providing energy for many biochemical processes in the body. The double bonds distributed throughout fatty acid carbon chains are a characteristic of unsaturated vegetable oils. They are more structurally diverse in polyunsaturated fats and oils with the greater preponderance for carbon-to-carbon double bonds distributed in the carbon chains. These double bonds are susceptible to generating free radicals. This article considers potential problems that proponents of the prevailing diet-heart cholesterol paradigm of the past 60 years may have neglected. It also presents the possible consequences of abandoning the evolutionarily inherited foods containing extracted natural saturated and monounsaturated fats and oils. Furthermore, the article addresses the contribution of docosahexaenoic and eicosapentaenoic acids to immunity and the possible
\end{abstract}

"Corresponding author.

How to cite this paper: Roccisano, D., Kumaratilake, J., Saniotis, A. and Henneberg, M. (2016) Dietary Fats and Oils: Some Evolutionary and Historical Perspectives Concerning Edible Lipids for Human Consumption. Food and Nutrition Sciences, 7, 689-702. http://dx.doi.org/10.4236/fns.2016.78070 
connection of excess consumption of omega- 6 fatty acid to the marked rise in obesity and other non-communicable diseases in modern civilization.

\title{
Keywords
}

\author{
Saturated Fats, Polyunsaturated Fatty Acids, Monounsaturated Fatty Acids, Diet-Heart Hypothesis
}

\section{Introduction}

What were the mechanisms that gave early hominids the impetus to develop the existing phylogenetic stock in the current form? Out of all the diets that have reached the human population over the past six decades, one of the most interesting is the "paleo diet". In the foods consumed by our ancestors, the fats and oils came from animals and plants in the natural form. Thus, they were not exposed to the industrially extracted forms of "vegetable oils" consumed by modern humans. Prehistoric and archaeological digs and animal "kill sites" indicated that our ancestors including hunter-gatherer societies consumed animal fats and fatty organs in preference to lean muscle meat.

\subsection{Paleo}

The recent "Paleo diet" fad gleaned from paleoanthropological studies appeared to be based on a presumption that the composition of our ancestral diet varied according to the seasonal changes. The food consumed by various species of omnivorous hominins in the pre-agricultural era was sufficient to supply the necessary nutrients to enable their growth, development (i.e. body and internal organs including the brain) and survival [1]. In hunter and gatherer circumstances, food would have been cooked with animal fat and in "the natural juices" supplemented with foraged vegetables and fruits according to the environmental availability. Their diet gave them the essential amino acids, fatty acids, vitamins and the minerals necessary for the building up of all the body components [2]. Furthermore, such nutritional components are required for the synthesis of hormones and enzymes that are involved in the generation of energy that drives the human behaviours, intellect, emotions and reproductive capacity, which have successfully propelled our species into the 21 st century.

\subsection{Evidence for Modern Understandings}

The delivery of many of the essential nutrients and vitamins, and functioning of the hormonal processes are dependent on the types of fats consumed [3]. Many vitamins will not absorb into the body, if there are insufficient fats of the correct type in the diet. Indeed, the important fat-soluble vitamins $\left(\mathrm{A}, \mathrm{D}_{3}, \mathrm{E}\right.$ and $\left.\mathrm{K}_{2}\right)$ work synergistically with each other and are better assimilated via saturated fats in the diet. Mediterranean salads, which use olive oil in the dressing, are renowned for their enhanced nutrient absorption.

Analysis of fossil bones and teeth using modern techniques, such as isotope analysis and X-ray microanalysis or use of the electron microscope [4] has helped us to understand the composition of ancient diets and the ancient diets and dietary habits.

During prehistoric evolution, hominins obtained the essential polyunsaturated fatty acids (PUFAs), omega-6 and omega-3 by consuming fruit, vegetables, seeds and nuts, and animal organ meats including marine life respectively. Twentieth-century findings indicated that the essential fatty acids contained in such foods were necessary for human neurological development [5].

\subsection{Ancient Production and Composition}

The settled communities of the agricultural era had the advantage of stability and time to discover the methods for oil extraction and identify, which oils were safe to consume and barter. Plio-Pleistocene hominins often provide us a picture of ancestral lifestyles, early dietary practices, and cultural activities. However, modern researchers have largely neglected the possible significance of the ancestral nutritional intake, the eating habits and any potential influence which has informed biological development of extant humans. Nevertheless, recent advances in nutrition have led to the elaboration of some questionable, but plausible popular spin-offs, such as 
the Paleo or Caveman Diet. However, "Darwinian" and "Evolutionary medical" analyses may identify the significance of an "ancient diet" on the evolution of the parts of the modern human body [6]-[8].

With time, increased understanding of agricultural processes by early humans, eventually generated multiple plants for seed crops and animal feed for their domesticated animals. These practicalities obviated the need for hunting and gathering. Development of fermentation and food preserving methods followed the capability of accessing olive fruit for oil extraction. Such events led to large-scale cultivation, harvesting and production of desirable commodities in adequate quantities for bartering, trading or gifting, as well as for tribal use. The predominantly consumed edible oils of history have been identified as the oil from the olive cultivations in regions of Mediterranean and subtropical climates, and oil from the coconut and palm in the hotter equatorial and subtropical climates. These extracted oils consist predominantly of monounsaturated fatty acids, (e.g., olive oil) and significantly higher levels of saturated fats in the palm and coconut.

\section{Historical Observations}

According to the historical records, olive oil was one of the earliest vegetable oils prepared from seeds or fruits and evidence comes from 6000 BCE Galilee, in Israel [9]. Palm and coconut oil residues have been detected in earthenware artifacts in Egyptian pyramids, approximately 4000 BC. Much later, in the east, soybean oil may have been extracted for culinary purposes in Manchuria and China, at about 1000 AD [10]. However soybean oil, as a tradeable commodity did not appear much outside of China and possibly Japan, most likely because of its inferior storage and transport quality that resulted from undergoing rancid rapidly. Olive, coconut, and palm are the only extracted edible vegetable oils that have been used for both trading; and domestic consumption continuously from ancient times to the present day.

The advent of the knowledge on the chemistry of fats and oils in the late 1800s in France and Germany led to the application of new technologies into the industrial manufacturing of fats and oils. Three significant advances were made in this field: firstly, changing from oil extraction, via mechanical crushing to chemical solvent (hexane) extraction. Secondly, improving storage by application of preservation technologies to enable reduced rancidification' of extracted oils via the addition of antioxidants or refrigeration; thirdly, making an extension to the second advance by discovering the application of hydrogenation techniques to oils, which converted polyunsaturated oils into the texture of natural fats.

Hydrogenation drastically improved the storage properties of industrially extracted polyunsaturated oils (i.e. reduced rancidification) and provided extensive trading opportunities and the stability of oils required by the baking and other food industries. Before the development of refrigeration technology, attempts to export highquality butter from Australia to Britain failed, because it had to pass through the heat of the tropics. The rapid technological improvement of oilseed extraction in the late 19th and early 20th centuries and hydrogenation led to the birth of a whole new edible fats industry. Hydrogenation and incorporation of additives converted industrially extracted "vegetable" oils (e.g. cottonseed oil) into margarine that looks and taste like butter and other animal fats. Furthermore, this margarine was able to be made soft at refrigeration temperature, and thus had the advantage over butter in spreading easily over bread and similar foods.

A significant difference between the ancient and currently consumed modern polyunsaturated lipids is the latter has a very high content of omega- 6 fatty acids, compared to the edible oils of the Paleolithic and pre-agricultural eras, or even ancient societies.

Despite industrial mass-production and export of varieties of polyunsaturated vegetable oils, people in different cultures/countries still consume many saturated fats as a significant part of their diet. Tibetans regularly consume large quantities of yak butter. On the Indian sub-continent, with the historical influence of Ayurvedic medicine, there is continued consumption of coconut oil, butter, and ghee. Furthermore, rural-based Chinese have a preference for lard and other pork saturated fat products, despite; the availability of modern Western-style processed and cheaper vegetable oils.

\subsection{Current Hunter Gatherer and Primate Evidence}

Identification of the types of Paleolithic food, hominins would have consumed is not a straightforward process. Intelligent derivation from the diets and dietary habits of the hunter and gatherer tribal groups still living in undeveloped parts of the globe, preferably those with minimal interaction with modern civilizations may provide some necessary information. Such groups may include peoples located in the remote highlands of New Guinea 
and the jungles of Southern America, or the Pygmies of central Africa, iKungs of South Africa, Agta of the subtropical Philippines, or Eskimos of the frozen Arctic (waste) lands of the North Alaska. Observations on the dietary habits of primates living in some parts of the world may also assist [11]. Paleontological and anatomical specialists are reluctant to comment with absolute certainty on the food types that were available to different hominin Paleolithic groups, which may have contributed to our evolutionary process [12].

\subsection{Fire/Cooking and Weapons}

The discovery of fire and learning to use it for cooking food increased the selection and the availability of dietary food sources from the environment. Use of fire, may also have improved cooking processes which in turn also have contributed to associated evolutionary changes of the human body' [13]. Furthermore, learning to use fire for cooking may have helped them to learn and practice methods of food preservation (e.g. drying meat and fish) and storage to be used during the periods of harsh climatic conditions or seasonal changes. Also, the discovery of fire would have assisted early humans to live in cold climatic zones, where they could not have lived before, and also protect themselves from predators who also occupied the same terrain and environment.

Learning to make tools and use them in hunting and preparation of food may have further increased the selection of available food sources from the environment and also may have enhanced ingestion and improved digestibility of the consumed foods. Therefore, development of weapons may also have contributed to the cooking processes which may also have contributed to associated evolutionary changes of the human body. These changes may not be limited to the jaw and dentition, but also to other parts of the gastrointestinal tract. Evolutionary adaptations in response to the omnivore diet, seen in the human digestive tract (i.e. presence of simple stomach, reduction in the length and the size of the intestines, particularly the caecum) may have resulted from learning to cook their food, which enhanced ingestion and improved digestibility of the consumed diet products.

\subsection{Adaptation}

Our ancestors may not have made deliberate choices in the selection of different foods from the environment. They may have foraged commonly available foods (i.e. fruits, nuts and other plants) and hunted animals in less harsh temperate conditions. In extreme or harsh environments, ancestors may have largely depended on high protein fatty diets obtained via hunting [14]. Therefore, the omnivorous adaptation of the digestive tract of early humans may have helped them to survive in environments changing from less to harsh conditions

\subsection{Available Foods, Protein, Energy Foods, and Vegetables}

Hominins survived by consuming protein based diets. This is confirmed by the survival of the Inuit people in the Arctic, who consume proteins and fat that come from the animals living in the same environment. The source of food for Inuit people was marine life (i.e. the primary source) and other wildlife living in the Arctic environment. Isotopic analysis of the remains of Upper Paleolithic hunter-gatherers from restricted Arctic ecosystems has revealed that they consumed animal proteins and fat at rates higher than Arctic foxes [15].

Other early human groups in different environments consumed both animal and plant-based foods. Energy from calorie intake may have come from (besides natural fats and oils) the natural sugars contained in fruits and possibly starchy vegetables, as well as honey from bees. This presumption is based on analysis of compromised dentition and advanced tooth decay after the transition from the more demanding hunter-gatherer to the agricultural lifestyle.

During the Neolithic revolution, new types of food preservation and processing techniques were created leading to the development of new food products that could be stored for extended periods of time. Time freed from food gathering was better used for the development of tools, weapons and fermentation techniques. The latter was applied for the preparation of bread, wine, and beer-making [16]. Similarly, early humans discovered simple methods for the extraction of edible vegetable oils from fruits and seeds available in the local ecology. Oil extraction for domestic use was carried out by a single individual, by a family group, or acquired through a gift-type economy, by bartering or trading for essentials like salt and stone tools (e.g. obsidian) [17]. The storage quality of the extracted oils (i.e. how quickly the oil became rancid) at room temperature would have determined the type of oil selected for consumption. The storage quality was also determined by the geographic or ecological environment or from a modern perspective (to which the ancients could be excused as being oblivious), the 
percentage of saturated and unsaturated fatty acids in the oil. Saturated fatty acids promoted the stability of the oil, while unsaturated fatty acids rapidly became rancid due to oxidization rendering such oils unfit for human consumption. Therefore, the oils extracted in prehistoric periods could only be the types that remained stable at the environmental temperature. A high percentage of saturated or monounsaturated fatty acids rendered the oil relatively stable under normal atmospheric conditions in contrast to any oils that had a significant proportion of polyunsaturated content. Experimental data reveal that coconut oil left exposed often survived up to a year without going rancid, whereas most vegetable oils go rancid within days under the same conditions.

Which fats were involved in the evolution of the human body? The answer is, many, if not all of them. In the pre-agricultural era, fats would have been derived from plant or animal foods obtained from their environment. These fats were integrated as part of the consumed foods and would have remained in the non-extracted form and from today's nutrition science perspective, would have consisted of saturated, monounsaturated and polyunsaturated fatty acids as well as the even more highly unsaturated omega-3 fatty acids Docosahexaenoic (DHA) and Eicosapentaenoic (EPA) Acids essential for neurological development. Humans do not readily synthesize the highly unsaturated omega- 3 including the more common omega- 6 fatty acids, which therefore have to be obtained from the diet. For this reason, they are therefore referred to as essential fatty acids. These fatty acids, when obtained from natural food sources and processed in the human body, are regarded as optimally not exceeding the optimal range of 1:1 (i.e. omega-3 to omega- 6 fatty acid ratio) [18] [19]. The majority of the modern diets use industrially extracted vegetable oils and their consumption of omega- 3 to omega- 6 ratio has spiralled out to 1:10 and in some instances 1:20 or more in the diets of some demographics in the United States of America. These unbalanced ratios, being a departure from the optimal 1:1 ratio, when placed together with a deficiency in omega-3 fatty acids, may be generating unacceptable levels of possible pro-inflammatory reactions in the population as a whole. To make matters worse is that concurrent with the ratio imbalance, is that there continues to be a proliferation and an excess consumption of omega- 6 fatty acids in the Western diet, which will make it difficult to eradicate a possible contributing cause of the increase in many inflammation-based noncommunicable diseases. Despite the blood-brain barrier, the brain is particularly sensitive to changes from the 1:1 ratio of omega-3 to omega- 6 fatty acids [2] [20] [21]. Consumption of omega- 6 fatty acids in excess amounts in most western diets, may be the cause of a range of non-communicable diseases such as cancer, diabetes, obesity, Alzheimer's disease, heart disease, hypertension and dementia [1] [18] [19] [22]-[26].

Humans eventually adapted to which extracted fats and oils? Early humans have been consuming saturated animal fats from the animals they hunted. The only extracted vegetable oils available to them were olive, coconut, and palm oils, which predominantly contained saturated and monounsaturated fatty acids. Polyunsaturated fatty acid containing vegetable oils as experienced in the "modern-day form" were not available to the early humans and would have been limited to being consumed as part of foods as a whole and not separately from the foods as found by hunting and gathering.

Ancient use of the extracted saturated and monounsaturated fat oils is supported by chemical analysis of 8000-year-old Early Bronze Age jar fragments and earthenware jars found in pre-Jewish settlements in Lower Galilee, in Israel. Later evidence of the use of extracted palm, coconut, and olive oil is derived from 4000-yearold urns and amphorae discovered in the pyramids of Egypt and a large quantity of palm oil found in a tomb near Abydos. The Egyptians were quite advanced in many medical activities and formulations, and it is entirely conceivable that they were capable of extracting many oils (including those of a polyunsaturated nature) for both medical and cosmetic as well as embalming applications. However, for culinary purposes they traded and consumed the three edible oils, olive, coconut and palm, similar to other people groups. Palm oil with its origins in West Africa, along with olive oil from the Middle East, were frequently exported and traded by the Phoenicians throughout the Mediterranean.

Modern medical science has identified that unsaturated fatty acids omega- 3 and omega- 6 are essential for the fetal neurological and reproductive development [18] [27]-[29]. They are also necessary for optimal cardiovascular and endocrine functioning of adult humans [30] [31].

The highly unsaturated oils found in marine life have been acknowledged as an important source of the EPA and DHA fatty acids. These fatty acids have been identified in the 20th century as critical in the neurological development of the eyes and brains of young infants. Although our bodies may produce minor amounts, it is still necessary to obtain them from the foods that we consume as part of a balanced diet. During pregnancy and lactation, the mother is the prime source of omega-3 fatty acids for the developing child. Therefore, the mother's diet must include an adequate intake of omega-3 fatty acids. 


\section{Molecular Structure and Sources of Some Historically Consumed Fatty Acids}

Fats and oils are composed of fatty acids. The fatty acid is a molecule with long carbon chain, where the carbon bonds are occupied by hydrogen atoms and the chain is capped with a carboxyl group. Saturated fats are simple straight chains of carbon atoms with no double bonds between carbon atoms (Figure 1). Mono and polyunsaturated fatty acids have a single and more than two double bonds between carbon atoms respectively [32] (Figure 4 and Figure 5).

\subsection{Lauric Acid}

Lauric acid, the primary saturated fatty acid found in coconut oil, has straight-chain of 12-carbon atoms (Figure 1). This particular fatty acid is also present in breast milk of humans and dairy cattle [33] [34].

Other medium straight-chain saturated fatty acids are caprylic acid ( 8 carbon atoms), caproic acid (6 carbon atoms) (Figure 2) and capric acid (10 carbon atoms), which are found in goats' milk fat and are responsible for the distinctive goat-like smell [35] [36].

\subsection{Stearic Acid}

Stearic acid is an 18-carbon straight-chained saturated fatty acid (Figure 3) readily found in cattle fat, hence referred to as stearic acid. Diets high in stearic acid reduced total and low-density lipoproteins cholesterol levels, but plasma triglyceride and high-density lipoprotein cholesterol levels remained unchanged in humans [37]-[39]. This indicates some beneficial effects of saturated fatty acids, in particular, a surprise for many, in the ingestion of red meat with stearic acid content.

\subsection{Oleic Acid}

Oleic acid, a monounsaturated fatty acid with a single C-C double bond and exists naturally in cis configuration (Figure 4). It is found in olive oil and is less likely to degrade quickly and oxidize under room temperature conditions and is vastly superior compared to polyunsaturated fatty acids found in most vegetable oils $[40]$.

Unsaturated vegetable oils have two or more double bonds distributed throughout the carbon chain, which becomes more structurally diverse with the greater preponderance of carbon-to-carbon double bonds distributed through the carbon chains of the polyunsaturated fats and oils, in contrast with saturated fatty acid (Figure 5). This molecular configuration makes the oils remain liquid even under cold, refrigerated environments. Hence, the commercial preference is for their use in refrigerated displays of stored foods $[41]$.

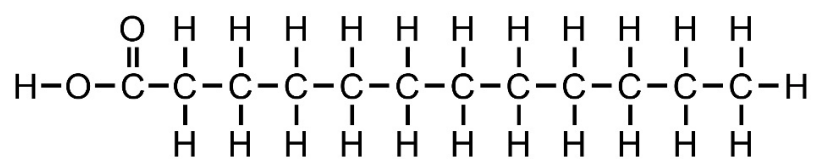

Figure 1. Molecular structure of Lauric acid (a saturated fatty acid).<smiles>CCCCC(=O)O</smiles>

Figure 2. Molecular structure of caproic acid.<smiles>CCCC(C)C(C)C(C)C(C)C(C)C(C)CCCC(C)=O</smiles>

Figure 3. Molecular structure of stearic acid, a saturated fatty acid. 
Fats and oils consumed in a diet are triglycerides. A triglyceride is formed by the combination of three fatty acid molecules with a glycerol molecule through ester bonds (Figure 6) [32]. The body utilizes triglyceride molecules to transport many different types of fats to the required locations and to store the excess fat in adipose cells [42].

\section{20th Century Advances}

A major problem with the ancient traditional methods (e.g., grinding) of vegetable oil extraction was the rapid degradation of the oil when exposed to light, heat, moisture and oxidation rendering such derived oils useless for human consumption (Table 1). However, the invention of new technologies to extract oils, made possible to produce oils from many alternative plant sources that were infrequently used or not in use before. Furthermore, rapid degradation of the oils was prevented by the new techniques of refrigeration or hydrogenation. The outcome of the technological advances was the availability of many classes of fats and oils (i.e. monounsaturated,

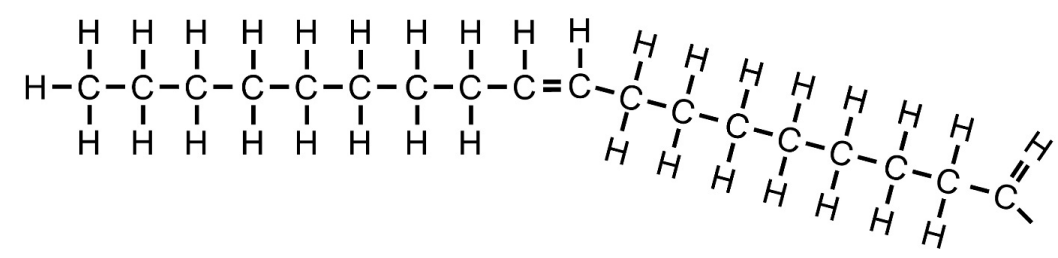

Figure 4. Molecular structure of oleic acid-cis molecular configuration.<smiles>CCCCCCCCCCCCC(C)C</smiles>

Saturated Fatty Acid<smiles>CCC=CCC=CCC=CC=O</smiles>

Unsaturated Fatty Acid

Figure 5. The molecular structure of a saturated fatty acid compared to an unsaturated fatty acid.

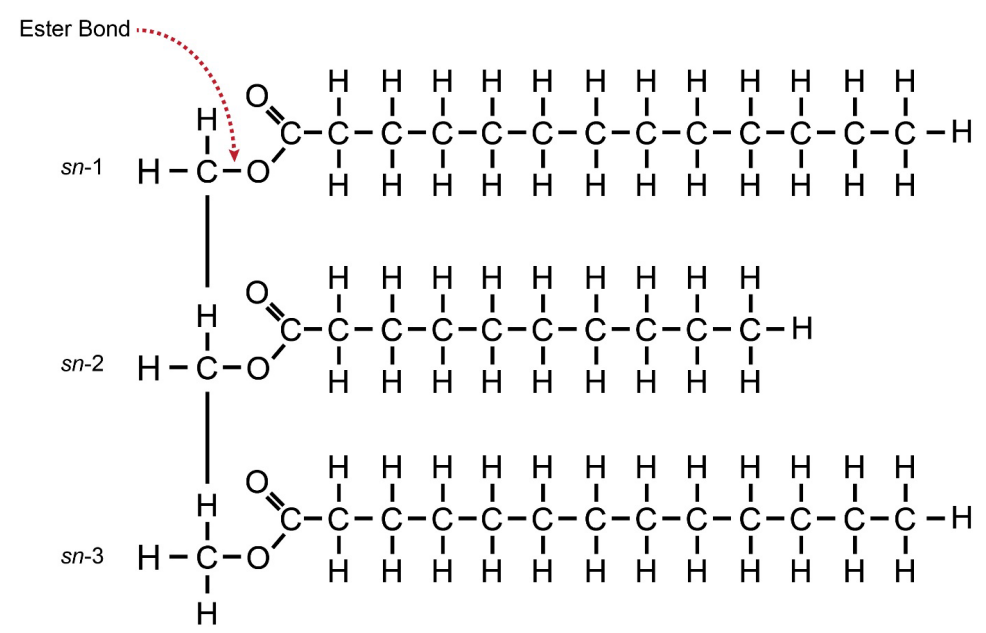

Molecular structure of a triglyceride molecule. $\mathrm{sn}$ = stereospecific numbering

Figure 6. Molecular structure of triglycerides. 
polyunsaturated oils, solid fats, and butter substitutes) that could be stereochemically manipulated for possible human consumption and a boon to the food industry. From an evolutionary perspective, there is a case to be made that the human body may need time to adapt gradually to metabolize them (i.e. possibly even over a very extended period) to reduce the above mentioned possible harmful effects of the long-term consumption of these newly introduced artificial fats.

\subsection{Mass Production of New Oils}

Vegetable oils were used for traditional soap making. In the late 1800 s to early 1900 s, as new refining, bleaching and deodorizing techniques and high heat oil extracting methods led to the production of oils with a neutral taste, which could be used for a variety of cooking purposes, in addition to soap making. The new industrially extracted oils were also very cheap to produce, and therefore very readily adapted for use in domestic and commercial cooking, frying and in baking industries. Furthermore, hydrogenation produced cheap margarine, and they gradually replaced natural fats, butter, lard and tallow in cooking and baking recipes. These advances were also accompanied by the development of improved methods for preservation and storage of the new polyunsaturated vegetable oils. Hydrogenated oils and fats were cheap, but could be made to have the appearance, texture and taste similar to natural products. The spread of refrigerated margarine over the bread was much easier than the spreading of chilled butter over bread. These features made the hydrogenated products attractive but over the course of the twentieth century have seemed to generate some harmful effects on human organ systems and tissues.

Vegetable oils are liquid at room temperatures; the majority of their molecules have double bonds interspersed in the carbon chains. Unlike saturated fatty acids, molecules of polyunsaturated fatty acids are distorted, and do not physically pack together very well. Thus, they remain liquid under refrigeration. Furthermore, oxidation and the creation of reactive molecular fragments occurs readily by any of the following processes: conventional heating during the cooking process, climatic or inappropriate room storage conditions, exposure to light and radiation, and even the body's metabolic processes. Whenever the tenuous double bonds in the unsaturated vegetable oil molecules are broken, the process of rancidity is hastened. Oxidation may also be accelerated during the cooking process, or continue to oxidize by the body's metabolic processes after being ingested, thereby extending free radical generation leading to chronic inflammation with eventual cumulative cellular damage [43] over a lifetime of consumption [26].

\subsection{Effect of Molecule Break Up/Degradation on Immunity}

The reactivity of the fragmented molecules can generate immunosuppressive tendencies: firstly by decreasing the body's resistance to infectious diseases [26] [43] [45]-[47]; secondly, by providing a "springboard" for the proliferation and development of new cancerous cells. The inherent instability of polyunsaturated oils in general, trigger/support cancer in nutritionally compromised individuals. Some authors have suggested that excess polyunsaturated fatty acids in the skin have a causal relationship with skin cancers [26] [48]-[50]. In other words, a diet highly inclusive of polyunsaturated vegetable oils, combined with excessive sun exposure, is a potential recipe for increased incidence of melanomas. The mechanism appears to be an interaction between the ultraviolet parts of the light spectrum with the polyunsaturated molecules in the skin, which accelerates the oxidation breakdown into free radicals.

Arachidonic acid has a regulatory role in the development of the immune system in early stages. However, high dietary intake of linoleic acid (omega-6), could lead to increased conversion of it into arachidonic acid in cells and this, in turn, may increase production of pro-inflammatory series 2 prostaglandins and series 4 leukotrienes. Thus, this may predispose individuals to allergic disorders (via effects on T and B cells) and also enhances allergic inflammatory mechanisms. Therefore, the effects of excess omega- 6 fatty acids on the immune system could be detrimental [51].

\section{Rise of Non-Communicable Diseases}

Consumption of omega-3 and omega-6 fatty acids in correct proportion is necessary for intellectual, cognitive and social skills development in homo-sapiens [52]. Findings of two large studies (Sydney Diet Heart Study (1966-1973) and Minnesota Coronary Experiment (1968-1973) indicated that replacement of naturally evolved dietary saturated fats with oils rich in linoleic acid (omega-6 fatty acid) increased the chance of mortality from 
Table 1. Approximate fatty acid content concentration in commonly consumed fats and oils.

\begin{tabular}{|c|c|c|c|}
\hline Fat/oil & Saturated (\%) & Monounsaturated (\%) & Polyunsaturated (\%) \\
\hline Coconut oil & 91.92 & 6.16 & 1.91 \\
\hline Margarine, hard & 80 & 14 & 6 \\
\hline Butter, salted & 68.1 & 27.87 & 4.0 \\
\hline Butter, without salt & 68.1 & 27.87 & 4.0 \\
\hline Butter oil, anhydrous & 65.63 & 30.45 & 3.92 \\
\hline Ghee, clarified butter & 65 & 32 & 3 \\
\hline Palm oil & 51.57 & 38.7 & 9.73 \\
\hline Lard & 41.1 & 47.23 & 11.73 \\
\hline Cottonseed oil & 27.1 & 18.62 & 54.29 \\
\hline Rice bran oil & 20.96 & 41.81 & 37.23 \\
\hline Margarine, soft & 20 & 47 & 33 \\
\hline Peanut oil & 17.77 & 48.58 & 33.65 \\
\hline Soybean oil & 16.27 & 23.69 & 60.0 \\
\hline Sesame oil (dark) & 14.85 & 41.53 & 43.62 \\
\hline Sesame oil (light) & 14.85 & 41.53 & 43.62 \\
\hline Olive oil (extra light) & 14.19 & 74.99 & 10.82 \\
\hline Olive oil (extra virgin) & 14.19 & 74.99 & 10.82 \\
\hline Olive oil (refined) & 14.19 & 74.99 & 10.82 \\
\hline Olive oil (virgin) & 14.19 & 74.99 & 10.82 \\
\hline Corn oil & 13.6 & 28.97 & 57.43 \\
\hline Mustard oil & 12.59 & 64.33 & 23.1 \\
\hline Avocado oil & 12.1 & 73.8 & 14.11 \\
\hline Sunflower oil (linoleic) & 10.79 & 20.42 & 68.8 \\
\hline Grapeseed oil & 10.0 & 16.84 & 73.12 \\
\hline Walnut oil & 9.56 & 23.95 & 66.49 \\
\hline Hemp oil & 9 & 12 & 79 \\
\hline Almond oil & 8.59 & 73.19 & 18.22 \\
\hline Canola oil & 7.46 & 64.1 & 28.49 \\
\hline Safflower oil (linoleic) & 6.51 & 15.1 & 78.4 \\
\hline
\end{tabular}

coronary heart disease [53]. This may well have resulted from an increase in linoleic acid in cells of the body, which leads to the afore-mentioned increasing production of linoleic acid oxidized derivatives and pro-inflammatory prostaglandins and leukotrienes [32] [51]. The increase in pro-inflammatory mediators promotes chronic inflammation of the body, particularly endothelial cells of the arteries leads to coronary heart disease and stroke.

Recent findings suggest that meat from grass-eating animals could provide high levels of omega- 3 fatty acids compared to animals fattened on commercial wheat and corn-oriented feedlots [54] [55]. Furthermore, the meat of animals fattened on grain had high omega- 6 fatty acids, as grains are high in this fatty acid [56]. Therefore, 
humans consuming meat from animals fattened on grain may have elevated levels of omega- 6 fatty acids in the body, making them susceptible to coronary heart disease. High pro-inflammatory mediators in the body resulting from the consumption of diets high in omega- 6 fatty acids could also cause other health issues involving cancer, diabetes and Alzheimer's Dementia [26] [57].

Cancer is a non-communicable disease second only to heart disease. In response, the United States National Cancer Act (1971) recognised a Special Cancer Task Force. Nevertheless, 7.41 million people worldwide died of cancer in 2012 [58], an expected rise of new cases annually from approximately 14 million in 2012 to 22 million within 20 years [59]. (Globally, new cases of dementia per year and the figure is projected to reach at least 75 million by 2030 WHO Facts as at March 2015) [60]. The incidence of people with diabetes has jumped almost fourfold since 1980, and in 2012 the disease was directly responsible for 1.5 million deaths globally [61]. In 2012 cardiovascular disease, was responsible for 17 million deaths and this figure is expected to rise to 23 million in 2030 [62]. The highly publicized correlation between saturated fat and cholesterol with an increase in cardiovascular disease went unchallenged until the results of the famous long-term Framingham heart and cholesterol Massachusetts study was published [63].

Table 2, Table 3 and Table 4 illustrate the profound change in the fatty acid profiles of human lipid consumption for millennia before 1900 and the stark change in the food supply post- 1900 .

Table 2. Vegetable oils used from ancient times to pre-1900.

\begin{tabular}{cccc}
\hline \multirow{2}{*}{ Oils } & \multicolumn{3}{c}{ Fatty acid percentage (\%) } \\
\cline { 2 - 4 } & Saturated & Monounsaturated & Polyunsaturated \\
\hline Olive oil (extra virgin) & 14.19 & 74.99 & 10.82 \\
Coconut oil & 91.92 & 6.16 & 1.91 \\
Palm oil & 51.57 & 38.7 & 9.73 \\
\hline
\end{tabular}

[44].

Table 3. Animal fats and oils of pre-1900s.

\begin{tabular}{cccc}
\hline Fats/oils & \multicolumn{3}{c}{ Fatty acid percentage (\%) } \\
\cline { 2 - 4 } & Saturated & Monounsaturated & Polyunsaturated \\
\hline Butter, salted & 68.1 & 27.87 & 4.0 \\
Lard & 41.1 & 47.23 & 11.73 \\
Mutton fat* & 47 & 41 & 8 \\
Beef fat* & 50 & 42 & 4 \\
Tuna* & 27 & 26 & 37 \\
\hline
\end{tabular}

[44] $*[64]$.

Table 4. Selection of popular modern 20th century fats and oils.

\begin{tabular}{cccc}
\hline \multirow{2}{*}{ Fats/oils } & \multicolumn{3}{c}{ Fatty acid percentage (\%) } \\
\cline { 2 - 4 } & Saturated & Monounsaturated & Polyunsaturated \\
\hline Canola oil & 7.46 & 64.1 & 28.49 \\
Cottonseed oil & 27.1 & 18.62 & 54.29 \\
Safflower oil (linoleic) & 6.51 & 15.1 & 78.4 \\
Soybean oil & 16.27 & 23.69 & 60.0 \\
Sunflower oil (linoleic) & 10.79 & 20.42 & 68.8 \\
Peanut oil & 17.77 & 48.58 & 33.65 \\
\hline
\end{tabular}

[44]. 


\section{Will "Survival of the Fittest" Prevail?}

The proliferation of the modern-day epidemic of non-communicable diseases such as coronary heart disease, diabetes, cancer, Alzheimer's Dementia and many others, in part may indeed result from the consumption of industrially processed foods prepared with polyunsaturated vegetable oils and their artificial by-products. Most of these diseases have been regarded as appearing at old age, after the production of offspring. Therefore, conditions resulting from a predominant polyunsaturated artificial fat-based diet may not necessarily be a threat to the survival of the human race, whereby "survival of the fittest" may not apply. However, with time (perhaps over a sufficiently long enough time) the human body may micro-evolve to adapt to metabolize the artificial fats and oils of the modern diet without manifesting the above non-communicable diseases. This may occur if the composition of the current fats and oils (i.e. industrially extracted) remains the same. However this in itself is due to most observed human behaviors and attitudes may remain indeterminate.

\section{Conclusions}

We established firstly that early humans instinctively pursued the very highly unsaturated omega- 3 fatty acids found in greater amounts in animal organ meats and marine life. Consuming vegetables and fruit gave them alternative access to the more abundant polyunsaturated class of essential fatty acids that had higher omega- 6 content. Early hominins were omnivorous and able to simultaneously utilize the neurological and endocrinal advantages, by accessing the highly volatile omega-3 essential fatty acids primarily from animal and marine sources. These identifiable essential fatty acids were a necessary component of human physical, cerebral and ocular/visual development.

Secondly, it appears that although ancient polyunsaturated vegetable oils may have existed in similar form to those widely consumed in the past century or so, they were rarely consumed in the current manner. What we do know is that the most readily extractable fats and oils for human consumption had been those that had a high percentage of both saturated and monounsaturated fats.

Thirdly, modern consumption of high amounts of omega- 6 in food products may indeed generate unnecessarily elevated levels of inflammatory mediators throughout the body. This unprecedented and often excessive consumption of omega- 6 fatty acids takes the body into a chronic inflammatory status and in long-term, could cause serious health problems predisposing some population groups to manifest an increased incidence of the "new" non-communicable diseases.

Fourth, whenever populations move away from the 1:1, omega-3 and omega- 6 fatty acid ratio, this may affect increased inflammatory mediators and disturb immune function, making them more vulnerable to the trending epidemic, of twentieth-century non-communicable diseases, but also to the present increasingly antibiotic resistant infectious diseases (e.g. influenza and tuberculosis) that humanity experienced, at different times in the past.

\section{References}

[1] Cordain, L. (2007) Implications of Plio-Pleistocene Hominim Diets for Modern Humans in Evolution of the Human Diet. In: Ungar, P.S., Ed., Evolution of the Human Diet: The Known, the Unknown, and the Unknowable, Oxford University Press, Oxford, 363-383.

[2] Erasmus, U. (1996) Fats that Heal, Fats that Kill. 2nd Edition, Alive Books, Burnaby.

[3] Conlon, L.E., King, R.D., Moran, N.E. and Erdman Jr., J.W. (2012) Coconut Oil Enhances Tomato Carotenoid Tissue Accumulation Compared to Safflower Oil in the Mongolian Gerbil (Meriones Unguiculatus). Journal of Agricultural and Food Chemistry, 60, 8386-8394. http://dx.doi.org/10.1021/jf301902k

[4] Teaford, M.F. (2007) What Do We Know and Not Know about Dental Microwear and Diet? In: Ungar P., Ed., Evolution of the Human Diet, OUP, New York, 106-131.

[5] Swanson, D. (2012) Omega-3 Fatty Acids EPA and DHA: Health Benefits throughout Life. Advanced Nutrition, 3, 1-7. http://dx.doi.org/10.3945/an.111.000893

[6] Williams, G.C. and Nesse, R.M. (1991) The Dawn of Darwinian Medicine. Quarterly Review of Biology, 66, 1-22. http://dx.doi.org/10.1086/417048

[7] Henneberg, M. and Saniotis, A. (2012) How Can Evolutionary Medicine Inform Future Personalised Medicine? Personalised Medicine, 9, 171-173. http://dx.doi.org/10.2217/pme.11.99

[8] Saniotis, A. and Henneberg, M. (2013) Evolutionary Medicine and Future Humanity: Will Evolution Have the Final 
Word? Humanities, 2, 278-291. http://dx.doi.org/10.3390/h2020278

[9] McMathis, J. (2015) Ancient Pottery Unearthed in Israel Contains 8000 Year Old Olive Oil. Israel Journal of Plant Sciences, 62, 65-74. http://dx.doi.org/10.1080/07929978.2014.960733

[10] Shurtleff, W. and Aoyagi, A. (2007) History of Soybean Crushing: Soy Oil and Soybean Meal—Part 1. A Chapter from the Unpublished Manuscript, History of Soybeans and Soyfoods, 1100 B.C. to the 1980s. http://www.soyinfocenter.com/HSS/soybean_crushing1.php

[11] Wrangham, R.W., Conklin, N.L., Chapman, C.A. and Hunt, K.D. (1992) The Significance of Fibrous Foods for Kibale Forest Chimpanzees. In: Whiten, A. and Widdowson, E.M., Eds., Foraging Strategies and Natural Diet of Monkeys, Apes, and Humans, Oxford Scientific Press, Oxford.

[12] Ungar, P.S. (2007) Evolution of the Human Diet: The Known, the Unknown and the Unknowable. Oxford University Press, Oxford.

[13] Wrangham, R.W., Jones, J.H., Laden, G., Pilbeam, D. and Conklin-Brittain, N. (1999) The Raw and the Stolen: Cooking and the Ecology of Human Origins. Current Anthropology, 40, 567-594. http://dx.doi.org/10.1086/300083

[14] Ferraro, J.V., Plummer, T.W., Pobiner, B.L., Oliver, J.S., Bishop, L.C., Braun, D.R., Ditchfield, P.W., Seaman III, J.W., Binetti, K.M., Seaman, J.W., Hertel, F. and Potts, R. (2013) Earliest Archaeological Evidence of Persistent Hominin Carnivory. PLoS ONE, 8, e0062174. http://doi.org/10.1371/journal.pone.0062174

[15] Richards, M.P. and Hedges, R.E.M. (2000) Focus: Gough's Cave and Sun Hole Cave Human Stable Isotope Values Indicate a High Animal Protein Diet in the British Upper Palaeolithic. Journal of Archaeological Science, 27, 1-3. http://dx.doi.org/10.1006/jasc.1999.0520

[16] Rudolph, M.H. (1992) Chemical Evidence for Ancient Beer. Nature, 360, 24. http://dx.doi.org/10.1038/360024b0

[17] McMaster, S.F. (2007) Neolithic. Routledge, New York.

[18] Simopoulos, A.P. (2002) The Importance of the Ratio of Omega-6/Omega-3 Essential Fatty Acids. Biomedicine \& Pharmacotherapy, 56, 365-379. http://dx.doi.org/10.1016/S0753-3322(02)00253-6

[19] Simopoulos, A.P. (2008) The Importance of the Omega-6/Omega-3 Fatty Acid Ratio in Cardiovascular Disease and Other Chronic Diseases. Experimental Biology and Medicine, 233, 674-688. http://dx.doi.org/10.3181/0711-MR-311

[20] Stoll, A. (2001) The Omega-3 Connection. Simon and Schuster, New York.

[21] Allport, S. (2007) The Queen of Fats: Why Omega-3 Fats Were Removed from the Western Diet and What We Can Do to Replace Them. University of California Press, Berkeley.

[22] Vander Veen, D.K., Martin, C.R., Mehendale, R., Allred, E.N., Dammann, O. and Leviton, A. (2013) Early Nutrition and Weight Gain in Preterm Newborns and the Risk of Retinopathy of Prematurity. PLoS One, 8, e0064325. http://dx.doi.org/10.1371/journal.pone.0064325

[23] Cordain, L., Eaton, S.B., Sebastian, A., Mann, N., Lindeberg, S., Watkins, B.A., O’Keefe, J.H. and Brand-Miller, J. (2005) Origins and Evolution of the Western Diet: Health Implications for the 21st Century. American Journal of Clinical Nutrition, 81, 341-354.

[24] Calder, P.C. and Grimble, R.F. (2002) Polyunsaturated Fatty Acids, Inflammation and Immunity. European Journal of Clinical Nutrition, 56, S14-S19. http://dx.doi.org/10.1038/sj.ejen.1601478

[25] Harbige, L. (1998) Dietary n-6 and n-3 Fatty Acids in Immunity and Autoimmune Disease. Proceedings of the Nutrition Society, 57, 555-562. http://dx.doi.org/10.1079/PNS19980081

[26] Yam, D., Eliraz, A. and Berry, E.M. (1996) Diet and Disease-The Israeli Paradox: Possible Dangers of a High Omega-6 Polyunsaturated Fatty Acid Diet. Israel Journal of Medical Sciences, 32, 1134-1143.

[27] Wenstrom, K.D. (2014) The FDA's New Advice on Fish: It's Complicated. American Journal of Obstetrics and Gynecology, 211, 475-478. http://dx.doi.org/10.1016/j.ajog.2014.07.048

[28] Greenberg, J.A., Bell, S.J. and Ausdal, W.V. (2008) Omega-3 Fatty Acid Supplementation during Pregnancy. Reviews in Obstetrics \& Gynecology, 1, 162-169.

[29] Hornstra, G., Monique, D.M., van Houwelingen, A.C. and Foreman-van Drongelen, M.M.H.P. (1995) Essential Fatty Acids in Pregnancy and Early Human Development. European Journal of Obstetrics \& Gynecology and Reproductive Biology, 61, 157-162.

[30] Breslow, J.L. (2006) N-3 Fatty Acids and Cardiovascular Disease. American Journal of Clinical Nutrition, 83, S1477S1482.

[31] Smith, S.E.P., Li, J., Garbett, K., Mirnics, K. and Patterson, P.H. (2007) Maternal Immune Activation Alters Fetal Brain Development through Interleukin-6. Journal of Neuroscience, 27, 10695-10702. http://dx.doi.org/10.1523/JNEUROSCI.2178-07.2007

[32] Wiktorowska-Owczarek, A., Berezińska, M. and Nowak, J.Z. (2015) PUFAs: Structures, Metabolism and Functions. 
Advances in Clinical and Experimental Medicine, 24, 931-941. http://dx.doi.org/10.17219/acem/31243

[33] Steele, W. and Moore, J.H. (1968) The Effects of a Series of Saturated Fatty Acids in the Diet on Milk-fat Secretion in the Cow. Journal of Dairy Research, 35, 361-370. http://dx.doi.org/10.1017/S0022029900019099

[34] Yuhas, R., Pramuk, K. and Lien, E.L. (2006) Human Milk Fatty Acid Composition from Nine Countries Varies Most in DHA. Lipids, 41, 851-858. http://dx.doi.org/10.1007/s11745-006-5040-7

[35] Garton, G.A. (1963) The Composition and Biosynthesis of Milk Alipids. Journal of Lipid Research, 4, $237-254$.

[36] Haenlein, G.F.W. (2004) Goat Milk in Human Nutrition. Small Ruminant Research, 51, 155-163. http://dx.doi.org/10.1016/j.smallrumres.2003.08.010

[37] Bonanome, A. and Grundy, S.M. (1988) Effect of Dietary Stearic Acid on Plasma Cholesterol and Lipoprotein Levels. New England Journal of Medicine, 318, 1244-1248. http://dx.doi.org/10.1056/NEJM198805123181905

[38] Hunter, J.E., Zhang, J. and Kris-Etherton, P.M. (2010) Cardiovascular Disease Risk of Dietary Stearic Acid Compared with Trans, Other Saturated, and Unsaturated Fatty Acids: A Systematic Review. American Journal of Clinical Nutrition, 91, 46-63. http://dx.doi.org/10.3945/ajen.2009.27661

[39] Astrup, A., Dyerberg, J., Elwood, P., Hermansen, K., Hu, F.B., Jakobsen, M.U., Kok, F.J., Krauss, R.M., Lecerf, J.M., Le Grand, P. and Nestel, P. (2011) The Role of Reducing Intakes of Saturated Fat in the Prevention of Cardiovascular Disease: Where Does the Evidence Stand in 2010? American Journal of Clinical Nutrition, 93, 684-688. http://dx.doi.org/10.3945/ajen.110.004622

[40] Zribi, A., Jabeur, H., Aladedunye, F., Rebai, A., Matthäus, B. and Bouaziz, M. (2014) Monitoring of Quality and Stability Characteristics and Fatty Acid Compositions of Refined Olive and Seed Oils during Repeated Pan- and DeepFrying Using GC, FT-NIRS, and Chemometrics. Journal of Agricultural and Food Chemistry, 62, 10357-10367. http://dx.doi.org/10.1021/jf503146f

[41] Kochhar, S.P. and Henry, C.J.K. (2009) Oxidative Stability and Shelf-Life Evaluation of Selected Culinary Oils. International Journal of Food Sciences and Nutrition, 60, 289-296. http://dx.doi.org/10.1080/09637480903103774

[42] Bartelt, A., Bruns, O.T., Reimer, R., Hohenberg, H., Ittrich, H., Peldschus, K., Kaul, M.G., Tromsdorf, U.I., Weller, H., Waurisch, C. and Eychmüller, A. (2011) Brown Adipose Tissue Activity Controls Triglyceride Clearance. Nature Medicine, 17, 200-205. http://dx.doi.org/10.1038/nm.2297

[43] Mascioli, E.A., Bistrian, B.R., Babayan, V.K. and Blackburn, G.L. (1987) Medium Chain Triglycerides and Structured Lipids as Unique Nonglucose Energy Sources in Hyperalimentation. Lipids, 22, 421-423. http://dx.doi.org/10.1007/BF02537272

[44] Charts Bin Statistics Collector Team (2011) Fat Composition in Different Cooking Oils, ChartsBin.com, Viewed 27th June, 2016. Reproduced under Creative Commons Attribution-Non Commercial-Share Alike 3.0 Unported License. http://chartsbin.com/view/1961

[45] Azrad, M., Turgeon, C. and Demark-Wahnefried, W. (2013) Current Evidence Linking Polyunsaturated Fatty Acids with Cancer Risk and Progression. Frontiers in Oncology, 3, 224. http://dx.doi.org/10.3389/fonc.2013.00224

[46] Bartsch, H., Nair, J. and Wyn Owen, R. (1999) Dietary Polyunsaturated Fatty Acids and Cancers of the Breast and Colorectum: Emerging Evidence for Their Role as Risk Modifiers. Carcinogenesis, 20, 2209-2218. http://dx.doi.org/10.1093/carcin/20.12.2209

[47] Newsholme, E.A. (1977) Mechanism for Starvation Suppression and Refeeding Activity of Infection. The Lancet, 309, 654. http://dx.doi.org/10.1016/S0140-6736(77)92093-1

[48] Mackie, B.S., Mackie, L.E., Curtin, L.D. and Bourne, D.J. (1987) Melanoma and Dietary Lipids. Nutrition and Cancer, 9, 219-226. http://dx.doi.org/10.1080/01635588709513930

[49] Qi, M., Chen, D., Liu, K. and Auborn, K.J. (2002) N-6 Polyunsaturated Fatty Acids Increase Skin But Not Cervical Cancer in Human Papillomavirus 16 Transgenic Mice. Cancer Research, 62, 433-436.

[50] Lenihan-Geels, G., Bishop, K.S. and Ferguson, L.R. (2016) Cancer Risk and Eicosanoid Production: Interaction between the Protective Effect of Long Chain Omega-3 Polyunsaturated Fatty Acid Intake and Genotype. Journal of Clinical Medicine, 5, E25. http://dx.doi.org/10.3390/jcm5020025

[51] Reese, I. and Werfel, T. (2015) Do Long-Chain Omega-3 Fatty Acids Protect from Atopic Dermatitis? Journal of the German Society of Dermatology, 13, 879-885. http://dx.doi.org/10.1111/ddg.12780

[52] Previc, F.H. (2009) The Dopaminergic Mind in Human Evolution and History. Cambridge University Press, New York. http://dx.doi.org/10.1017/CBO9780511581366

[53] Ramsden, C.E., Daisy Zamora, D., Majchrzak-Hong, S., Faurot, K.R., Steven, K., Broste, S.K., Frantz, R.P., Davis, J.M., Amit Ringel, A., Suchindran, C.M. and Hibbeln, J.R. (2016) Re-Evaluation of the Traditional Diet-Heart Hypothesis: Analysis of Recovered Data from Minnesota Coronary Experiment (1968-73). BMJ, 353, i1246. http://dx.doi.org/10.1136/bmj.i1246 
[54] Ponnampalam, E.N., Butler, K.L., Jacob, R.H., Pethick, D.W., Ball, A.J., Edwards, J.E., Geesink, G. and Hopkins, D.L. (2014) Health Beneficial Long Chain Omega-3 Fatty Acid Levels in Australian Lamb Managed under Extensive Finishing Systems. Meat Science, 96, 1104-1110. http://dx.doi.org/10.1016/j.meatsci.2013.04.007

[55] Daley, C.A., Abbott, A., Doyle, S.P., Nader, A.G. and Larson, S. (2010) A Review of Fatty Acid Profiles and Antioxidant Content in Grass-Fed and Grain-Fed Beef. Nutrition Journal, 9, 10. http://dx.doi.org/10.1186/1475-2891-9-10

[56] Simopoulos, A.P. (2006) Evolutionary Aspects of Diet, the Omega-6/Omega-3 Ratio and Genetic Variation: Nutritional Implications for Chronic Diseases. Biomedicine \& Pharmacotherapy, 60, 502-507. http://dx.doi.org/10.1016/j.biopha.2006.07.080

[57] Roccisano, D., Henneberg, M. and Saniotis, A. (2014) A Possible Cause of Alzheimer's Dementia: Industrial Soy Foods. Medical hypotheses, 82, 250-254. http://dx.doi.org/10.1016/j.mehy.2013.11.033

[58] GLOBOCAN (2012) Estimated Cancer Incidence, Mortality and Prevalence Worldwise in 2012. http://globocan.iarc.fr/Pages/fact sheets cancer.aspx

[59] WHO (2015) Key facts about Cancer. World Health Organization. http://www.who.int/mediacentre/factsheets/fs297/en/

[60] WHO (2015) 10 Facts on Dementia. World Health Organization. http://www.who.int/features/factfiles/dementia/en/

[61] WHO (2016) 10 Facts about Diabetes. World Health Organization. http://www.who.int/features/factfiles/diabetes/en/

[62] WHO (2015) Cardiovascular Diseases (CVDs). World Health Organization. http://www.who.int/mediacentre/factsheets/fs317/en

[63] Willet, W.C., Stampfer, M.J., Manson, J.E., Colditz, G.A., Speizer, F.E., Rosner, B.A., Sampson, L.A. and Hennekens, C.J. (1993) Intake of Trans Fatty Acids and Risk of Coronary Heart Disease among Women. The Lancet, 341, 581-585. http://dx.doi.org/10.1016/0140-6736(93)90350-P

[64] Nutristrategy (2015) Fats, Cooking Oils and Fatty Acids. http://www.nutristrategy.com/fatsoils.htm

\section{Submit or recommend next manuscript to SCIRP and we will provide best service for you:}

Accepting pre-submission inquiries through Email, Facebook, Linkedin, Twitter, etc A wide selection of journals (inclusive of 9 subjects, more than 200 journals)

Providing a 24-hour high-quality service

User-friendly online submission system

Fair and swift peer-review system

Efficient typesetting and proofreading procedure

Display of the result of downloads and visits, as well as the number of cited articles

Maximum dissemination of your research work

Submit your manuscript at: http://papersubmission.scirp.org/ 